\title{
Tuning the switching pressure in square lattice coordination networks by metal cation substitution
}

Received 00th January 20xx, Accepted 00th January 20xx DOI: $10.1039 / \times 0 \times x 00000 x$

\author{
Shi-Qiang Wang, Shaza Darwish, Debobroto Sensharma, and Michael J. Zaworotko*
}

Coordination networks that undergo guest-induced switching between "closed" nonporous and "open" porous phases are of increasing interest as the resulting stepped sorption isotherms can offer exceptional working capacities for gas storage applications. For practical utility, the gate ad/desorption pressures $\left(\mathrm{P}_{\mathrm{ga}} / \mathrm{P}_{\mathrm{gd}}\right)$ must lie between the storage $\left(\mathrm{P}_{\mathrm{st}}\right)$ and delivery $\left(P_{d e}\right)$ pressures and there must be fast switching kinetics. Herein we study the effect of metal cation substitution on the switching pressure of a family of square lattice coordination networks $\left[\mathrm{M}\left(4,4^{\prime} \text {-bipyridine }\right)_{2}(\mathrm{NCS})\right]_{\mathrm{n}}$ (sql-1-M-NCS, M = Fe, Co and $\mathrm{Ni}$ ) with respect to $\mathrm{CO}_{2}$ sorption. The Clausius-Clapeyron equation was used to correlate $\mathrm{P}_{\mathrm{ga}} / \mathrm{P}_{\mathrm{gd}}$ and temperature. At $298 \mathrm{~K}, \mathrm{P}_{\mathrm{ga}} / \mathrm{P}_{\mathrm{gd}}$ values were found to vary from 31.6/26.7 bar $(\mathrm{M}=\mathrm{Fe})$ to $26.7 / 20.9 \mathrm{bar}(\mathrm{M}=\mathrm{Co})$ and $18.5 / 14.6$ bar $(\mathrm{M}=\mathrm{Ni})$. The switching event occurs within 10 minutes as verified by dynamic $\mathrm{CO}_{2}$ sorption tests. In addition, in situ synchrotron PXRD and molecular simulations provided structural insight into the observed switching event, which we attribute to layer expansion of sql-1-M-NCS via intercalation and inclusion of $\mathrm{CO}_{2}$ molecules. This study could pave the way for rational control over $\mathrm{P}_{\mathrm{ga}} / \mathrm{P}_{\mathrm{gd}}$ in switching adsorbent layered materials and enhance their potential utility in gas storage applications.

\section{Introduction}

New approaches to gas storage/delivery are needed in the "age of gas" to address the large energy footprint associated with existing technologies such as compressed or liquefied gas storage. ${ }^{1}$ Whereas physisorption holds promise for greatly improving the energy efficiency of industrial gas storage, it does not yet meet the prerequisites for practical deployment such as adsorbed natural gas (ANG) storage. ${ }^{2}$ This is at least partly because rigid physisorbents such as zeolites tend to suffer from inappropriate sorption isotherms (Langmuir or type $\mathrm{I}^{3}$ ), resulting in lower working capacity than the saturation uptake (Scheme 1a). ${ }^{4}$

Metal-organic materials (MOMs), ${ }^{5,6}$ such as metal-organic frameworks (MOFs) ${ }^{7,8}$, or porous coordination polymers/networks (PCPs/PCNs), ${ }^{9-12}$ have attracted attention from academic and industrial researchers thanks to their potential utility in the areas as broad as storage, separation and catalysis. ${ }^{13,14} \mathrm{~A}$ prominent feature of MOMs is their inherent modularity which enables fine tuning of structures through crystal engineering or reticular chemistry. ${ }^{15,16}$ However, although ca. 100,000 MOMs have been deposited in the MOF subset of the Cambridge Structural Database (CSD), ${ }^{17}$ most are rigid physisorbents that exhibit the aforementioned type I sorption isotherms. In contrast, flexible MOMs (FMOMs) or soft porous crystals (SPCs) can undergo guest-induced switching between nonporous and porous phases and exhibit perhaps the

Department of Chemical Sciences and Bernal Institute, University of Limerick Limerick V94 T9PX, Republic of Ireland. E-mail: Michael.Zaworotko@ul.ie

tElectronic Supplementary Information (ESI) available: Synchrotron PXRD patterns, water vapour sorption isotherms, TGA curves, Clausius-Clapeyron calculations, etc. See DOI: $10.1039 / x 0 x x 00000 x$ most desirable isotherm type, a stepped or type F-IV isotherm. ${ }^{18-20}$ The optimal type F-IV isotherm would offer gate adsorption $\left(\mathrm{P}_{\mathrm{ga}}\right)$ and desorption $\left(\mathrm{P}_{\mathrm{gd}}\right)$ pressures that lie between the storage $\left(P_{s t}\right)$ and delivery $\left(P_{\text {de }}\right)$ pressures to enable high working capacity (Scheme 1b). There is little margin for error, however, as FMOMs that remain closed during adsorption ( $\mathrm{P}_{\text {ga }}$ $>\mathrm{P}_{\text {st }}$, Scheme $\left.1 \mathrm{c}\right)$ or open during desorption $\left(\mathrm{P}_{\mathrm{gd}}<\mathrm{P}_{\mathrm{de}}\right.$, Scheme 1d) will offer negligible working capacity. Furthermore, gas storage criteria for $\mathrm{P}_{\text {st }}$ and $\mathrm{P}_{\text {de }}$ could vary significantly in different circumstances. The ability to fine-tune the switching pressures

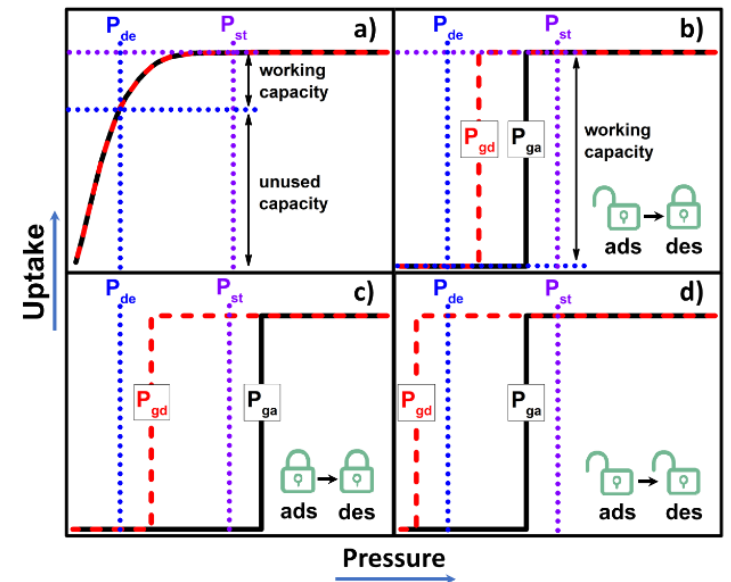

Scheme 1. Comparison of different types of gas sorption isotherms. (a) type I; (b) type F-IV $\left(\mathrm{P}_{\mathrm{de}}<\mathrm{P}_{\mathrm{gd}}<\mathrm{P}_{\mathrm{ga}}<\mathrm{P}_{\mathrm{st}}\right)$; (c) type F-IV $\left(\mathrm{P}_{\mathrm{de}}<\mathrm{P}_{\mathrm{gd}}<\mathrm{P}_{\mathrm{st}}<\mathrm{P}_{\mathrm{ga}}\right)$ and $(\mathrm{d})$ type F-IV $\left(\mathrm{P}_{\mathrm{gd}}<\mathrm{P}_{\mathrm{de}}<\mathrm{P}_{\mathrm{ga}}<\mathrm{P}_{\mathrm{st}}\right)$. Black solid line: adsorption; red dash line: desorption; $P_{g a}$ : gate adsorption pressure; $\mathrm{P}_{\mathrm{gd}}$ : gate desorption pressure; $\mathrm{P}_{\mathrm{de}}$ : delivery pressure; $\mathrm{P}_{\mathrm{st}}$ : storage pressure; ads: adsorption; des: desorption. 
in FMOMs is thus important to enable the development of bespoke adsorbent materials for gas storage/delivery. Thus far, to our knowledge, only a relatively small subset of FMOMs feature type F-IV isotherms and even fewer have been subjected to systematic studies that address how to control their switching pressures. ${ }^{21}$

Crystal-engineering approaches can be exploited to tailor structures, compositions and, therefore, properties of MOMs. ${ }^{22}$ In the context of FMOMs, ligand "linker" or metal "node" substitution can be used to modulate flexibility. ${ }^{23-26}$ Ligand functionalization was used to adjust the switching of parent sorbents such as MIL-53(Fe) and $[\mathrm{Co}(\mathrm{bdp})] \cdot .^{27-29}$ Regarding ligand substitution, we recently reported a family of two-fold interpenetrated FMOMs, X-pcu-n-Zn ( $n=5-8)$, which exhibited pronounced switching behavior with comparable uptakes but different switching pressures. ${ }^{30,31}$ Considerable attention has been paid to exploiting metal cation substitution to modulate FMOM platforms, however, it can be a challenge to retain the type F-IV sorption profile. ${ }^{32-37}$ For example, MIL-53(Cr or Al) were found to exhibit type $\mathrm{F}-\mathrm{I}$ isotherms for $\mathrm{CO}_{2}$ sorption, 32 while MIL-53(Fe or Sc) featured type F-IV isotherms. ${ }^{33,34}$ In addition, the $\mathrm{Co}$ and Fe variants of $[\mathrm{M}(\mathrm{bdp})]$ exhibited type F-IV isotherms, ${ }^{4}$ but their $\mathrm{Zn}$ and $\mathrm{Ni}$ analogues showed type I isotherms. ${ }^{35}$ The pillared-layer coordination networks, DUT$8(\mathrm{M})$, exhibited type F-IV (DUT-8(Ni)), type F-I (DUT-8(Co)) or type I (DUT-8(Cu)) isotherms upon $\mathrm{CO}_{2}$ sorption. ${ }^{36}$ Even though the zeolitic imidazolate frameworks [ $\left.\mathrm{M}(\mathrm{bim})_{2}\right](\mathrm{M}=\mathrm{Co}, \mathrm{Zn}$ and Cd) retained their switching nature, there a significant pre-step was observed in the Co and $\mathrm{Zn}$ variants. ${ }^{37}$ Herein we address the use of metal cation substitution to tune the switching pressure in a family of three square lattice (sql) coordination networks
$\left[\mathrm{M}(\text { bpy })_{2}(\mathrm{NCS})_{2}\right]_{n}$, sql-1-M-NCS $\left(1=\right.$ bpy $=4,4^{\prime}$-bipyridine, $\mathrm{M}=$ $\mathrm{Fe}, \mathrm{Co}$ and $\mathrm{Ni}$ ).

Square lattice (sql) coordination networks account for nearly half of reported 2D coordination networks $(\mathrm{CNs}) .{ }^{38}$ sql CNs with general formula $\left[\mathbf{M}(\mathbf{L})_{2}(\mathbf{A})_{2}\right]$ can be readily formed by selfassembly of octahedral metal ions (M), axial counter anions (A) and linear linker ligands (L). ${ }^{39}$ The prototypal noninterpenetrated sql $\mathrm{CN},\left[\mathrm{Cd}(\mathrm{bpy})_{2}\left(\mathrm{NO}_{3}\right)_{2}\right]_{\mathrm{n}}$, was reported by Fujita's group in $1994 .{ }^{40}$ This seminal work was followed by a series of studies that focused more upon the structural features of such networks rather than sorption properties until $\left[\mathrm{Cu}(\mathrm{bpy})_{2}\left(\mathrm{BF}_{4}\right)_{2}\right](\mathrm{ELM}-11)$ was investigated. ${ }^{41,42}$ ELM-11 was found to exhibit switching when exposed to gases such as $\mathrm{CO}_{2}$, $\mathrm{C}_{2} \mathrm{H}_{2}$ and $n$-butane. ${ }^{43-47}$ Its metal cation substituted analogue, [Ni(bpy $\left.)_{2}\left(\mathrm{BF}_{4}\right)_{2}\right](\mathrm{ELM}-31)$, also exhibits a type F-IV isotherm upon $\mathrm{CO}_{2}$ sorption but with different uptake and switching pressure. ${ }^{48}$ Nevertheless, the metal substitution strategy has not yet been fully exploited in the ELM-11 family.

Recently, our group reported the sorption properties of a previously known sql CN $\left[\mathrm{Co}(\text { bpy })_{2}(\mathrm{NCS})_{2}\right], 49$ sql-1-Co-NCS, 50,51 which is closely related to the ELM family. ${ }^{43,44}$ The $195 \mathrm{~K} \mathrm{CO}_{2}$ sorption isotherm of sql-1-Co-NCS was observed to be type FIV. ${ }^{50}$ High-pressure $\mathrm{CO}_{2}$ sorption at different temperatures exhibited type F-IV sorption profiles and the temperature vs switching pressure obeyed the Clausius-Clapeyron equation. Crystallographic studies revealed that the interlayer distance in the closed phase $(4.5 \AA)$ increased in the $\mathrm{CO}_{2}$ loaded phase $(5.4$ $\AA)$, although the location of $\mathrm{CO}_{2}$ molecules was not determined. ${ }^{50}$ In this contribution, we report the $\mathrm{Fe}$ and $\mathrm{Ni}$ analogues of sql-1-Co-NCS and their $\mathrm{CO}_{2}$ sorption profiles and switching kinetics.
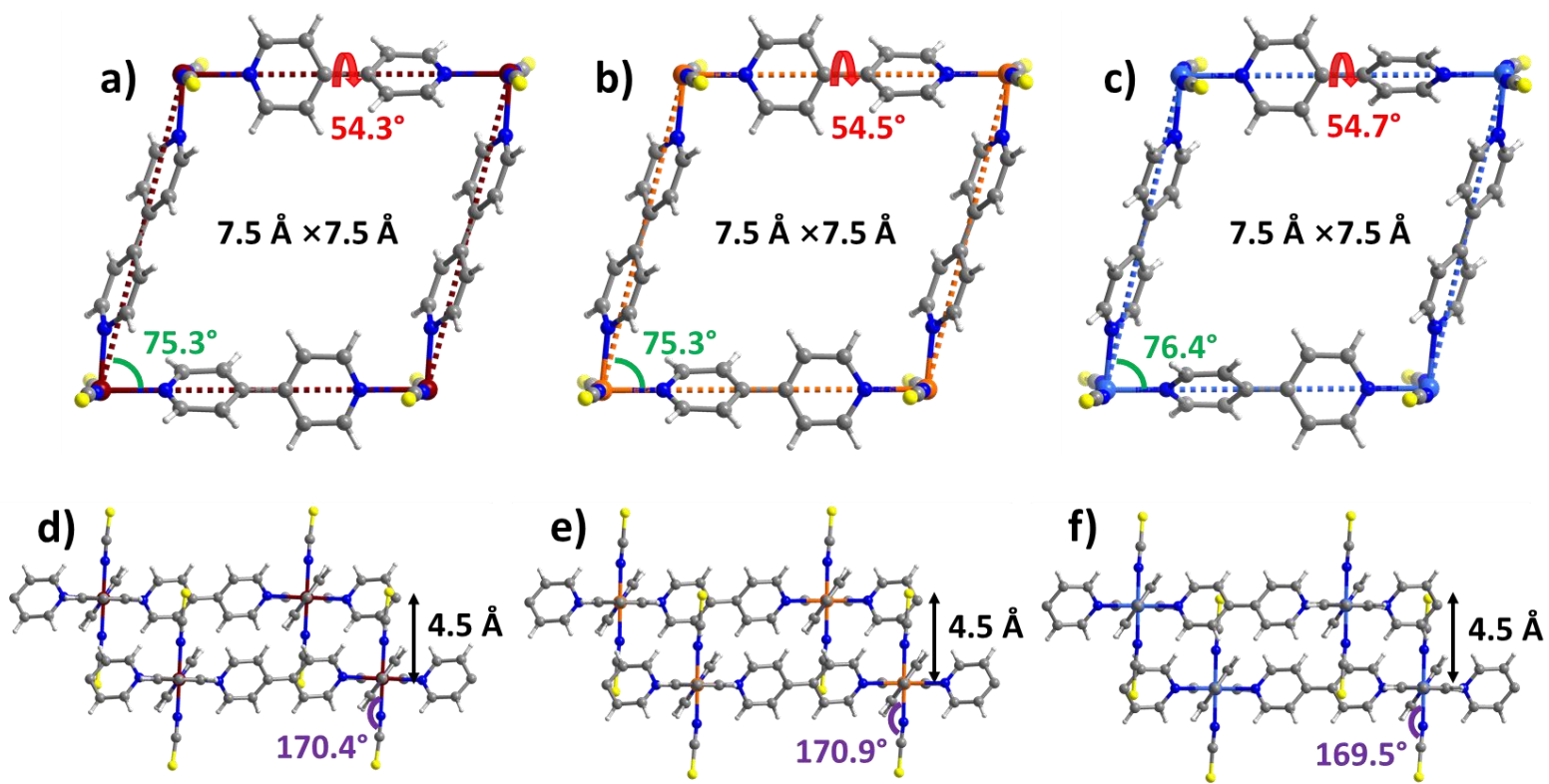

Fig. 1 Comparison of the crystal structures of sql-1-M-NCS. $a, d) M=F e ; b, e) M=C o ; c, f) M=N i$. 


\section{Results and discussion}

sql-1-M-NCS ( $\mathrm{M}=\mathrm{Fe}$ and $\mathrm{Ni}$ ) were synthesized by heating their precursors $\left\{\left[\mathrm{M}(\text { bpy })(\mathrm{NCS})_{2}\left(\mathrm{H}_{2} \mathrm{O}\right)_{2}\right] \cdot \text { bpy }\right\}_{n}$ at $50{ }^{\circ} \mathrm{C}$ in vacuo. These precursors were prepared by a water slurry method. The crystal structures of sql-1-Co-NCS and sql-1-Ni-NCS were previously determined by single-crystal X-ray diffraction ${ }^{50,52}$ and we determined the crystal structure of sql-1-Fe-NCS here by refinement of synchrotron PXRD data (Fig. S1 and S3a). The three sql-1-M-NCS CNs are comprised of $\mathrm{M}(\mathrm{II})$ cations coordinated to four equatorial bpy ligands and two axial NCS ligands. Their synchrotron PXRD patterns match well (Fig. S1). The effective cavity sizes ( $7.5 \AA \times 7.5 \AA$ ) and interlayer distance (4.5 $\AA$ ) are equivalent, although there are subtle differences in the torsion angle of bpy ligands $\left(54.3-54.7^{\circ}\right)$ and $\mathrm{M}-\mathrm{M}-\mathrm{M}(75.3$ - 76.4 ${ }^{\circ}$ and SC-N-M $\left(169.5-170.9^{\circ}\right)$ angles (Fig. 1). The terminal NCS ligands interdigitate with adjacent layers (Fig. 1df) to block the cavities in the closed phases of sql-1-M-NCS.

Although the cavity size and interlayer distance of sql-1-MNCS are comparable to those of ELM-11, the hydrophilicity of sql-1-M-NCS towards humidity is mitigated thanks to the utilization of the more hydrophobic NCS- anion (Fig. S4). Thermogravimetric analysis (TGA) revealed that sql-1-Ni-NCS exhibits better thermal stability $\left(c a .180^{\circ} \mathrm{C}\right)$ than its Fe and Co analogues (ca. $150^{\circ} \mathrm{C}$ ) (Fig. S5), which follows the empirical Irving-Williams series. ${ }^{53} 195 \mathrm{~K} \mathrm{CO}_{2}$ sorption studies revealed that sqI-1-M-NCS CNs exhibit the same saturation uptake (ca. $138 \mathrm{~cm}^{-3} \mathrm{~g}^{-1}$ ), equivalent to three $\mathrm{CO}_{2}$ molecules per formula unit (denoted as sql-1-M-NCS·3CO $\mathbf{C O}_{2}$ ), but with distinct $\mathrm{P}_{\mathrm{ga}} / \mathrm{P}_{\mathrm{gd}}$ values: Fe $(15 / 12 \mathrm{kPa})>\mathrm{Co}(10 / 8 \mathrm{kPa})>\mathrm{Ni}(4 / 3.5 \mathrm{kPa})$ (Fig. 2). Unlike ELM-11 which exhibits multi-step $\mathrm{CO}_{2}$ sorption isotherms at $195 \mathrm{~K}, 54,55$ sql-1-M-NCS registered single-step sorption isotherms although sql-1-Fe-NCS had a small sub-step with 17 $\mathrm{cm}^{-3} \mathrm{~g}^{-1}$ uptake between 11 and $15 \mathrm{kPa}$.

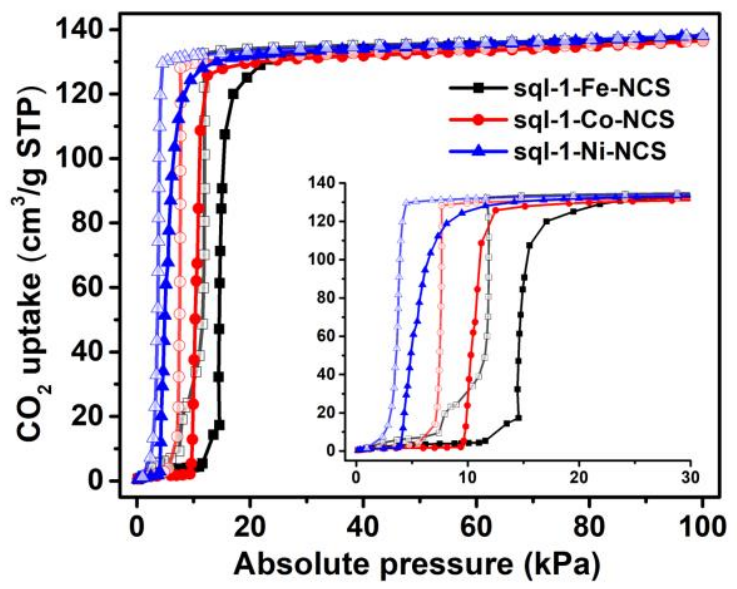

Fig. $2 \mathrm{CO}_{2}$ sorption isotherms for sql-1-M-NCS (M = Fe, Co, and $\mathrm{Ni)}$ at $195 \mathrm{~K}$. The solid and open symbols represent adsorption and desorption branches, respectively.

We next collected high-pressure (up to 38 bar) $\mathrm{CO}_{2}$ sorption isotherms on sql-1-M-NCS ( $\mathrm{M}=\mathrm{Fe}$ and $\mathrm{Ni}$ ) between 273 and 298 $\mathrm{K}(5 \mathrm{~K}$ intervals) as previously conducted for sql-1-Co-NCS (Fig. 3a,b and S6). The $\mathrm{P}_{\mathrm{ga}} / \mathrm{P}_{\mathrm{gd}}$ values for sql-1-Fe-NCS were $12.5 / 10.5,15.2 / 12.8,18.5 / 15.5,22.3 / 18.7,26.6 / 22.6$ and $31.6 / 26.7$ bar from 273 to $298 \mathrm{~K}$, respectively. In contrast, sql1-Ni-NCS was found to offer lower $\mathrm{P}_{\mathrm{ga}} / \mathrm{P}_{\mathrm{gd}}$ values: 6.5/5.1, 8.1/6.4, 10.1/7.9, 12.5/9.8, 15.2/11.9 and 18.5/14.5 bar from 273 to $298 \mathrm{~K}$, respectively. The $\mathrm{CO}_{2}$ sorption isotherms of sql-1M-NCS $(\mathrm{M}=\mathrm{Fe}$ and $\mathrm{Ni})$ revealed a relationship between the $\mathrm{P}_{\mathrm{ga}} / \mathrm{P}_{\mathrm{gd}}$ and temperature which obeys the Clausius-Clapeyron equation $d \ln P /(d(1 / T))=( \pm) \Delta H / R$ (Fig. 3c,d and S7). The phase transition enthalpies $\Delta \mathrm{H}$ (the signs of $\Delta H$ are negative/positive for adsorption/desorption, respectively, absolute values are
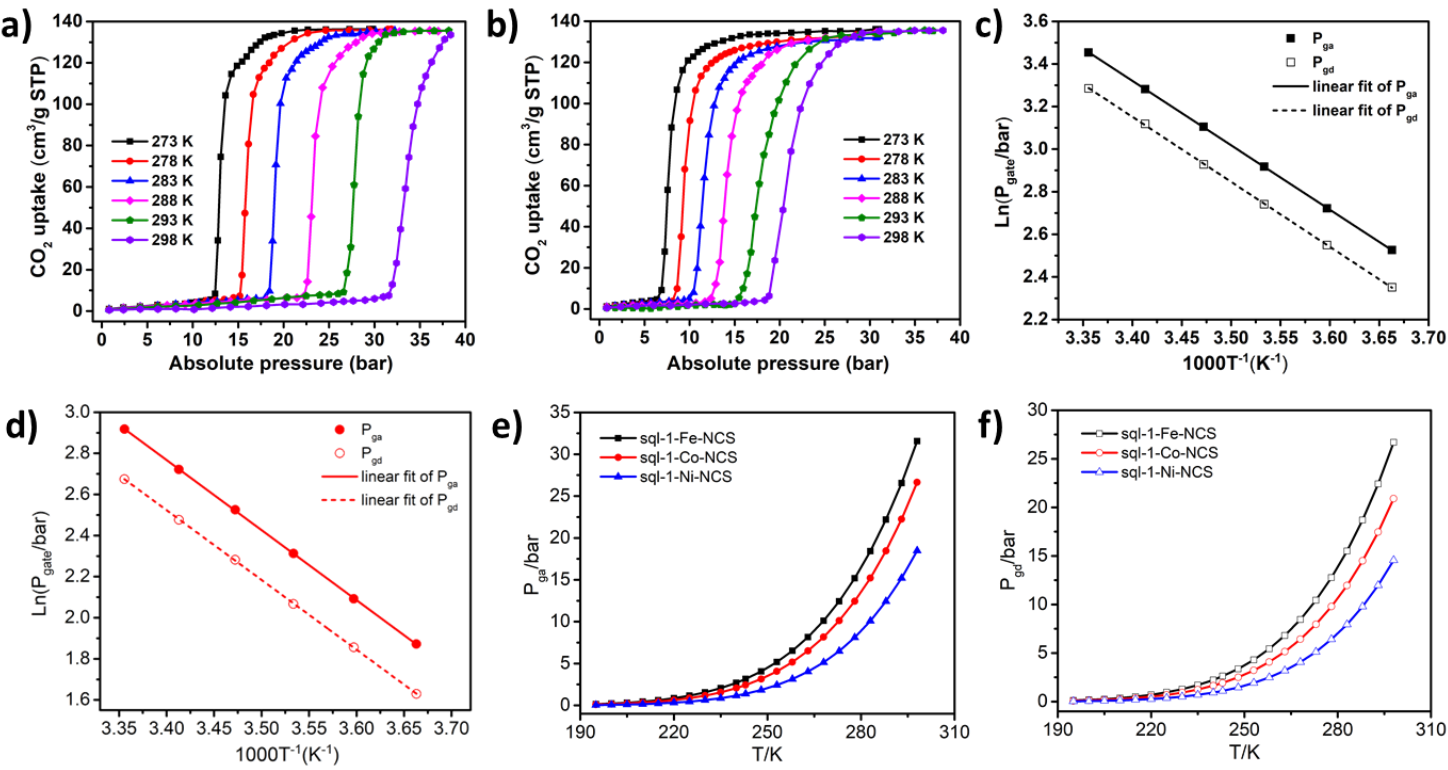

Fig. 3 High-pressure $\mathrm{CO}_{2}$ sorption isotherms of a) sql-1-Fe-NCS and b) sql-1-Ni-NCS. The linear fit of gate sorption pressure (LnP) and temperature $(1000 / T)$ using the Clausius-Clapeyron equation for $\mathrm{C}$ ) sql-1-Fe-NCS and d) sql-1-Ni-NCS. e) calculated $P_{\text {ga }}$ and f) $\mathrm{P}_{\mathrm{gd}}$ for sql-1-M-NCS (M = Fe, Co, and $\mathrm{Ni}$ ). 
used hereafter) were calculated to be $c a .25 .2$ and $28.4 \mathrm{~kJ} / \mathrm{mol}$ for sql-1-Fe-NCS and sql-1-Ni-NCS, respectively, $1.0 \mathrm{~kJ} / \mathrm{mol}$ lower and $2.2 \mathrm{~kJ} / \mathrm{mol}$ higher than that of sql-1-Co-NCS $(26.2$ $\mathrm{kJ} / \mathrm{mol}){ }^{50}$

One advantage for switching $\mathrm{CNs}$ is the switching pressure can be calculated at a given temperature once $\Delta H$ in the Clausius-Clapeyron equation has been determined. ${ }^{47,50} \mathrm{We}$ thus plotted calculated switching pressure $v s$ temperature from 195 to $298 \mathrm{~K}$ for sql-1-M-NCS ( $\mathrm{M}=\mathrm{Fe}, \mathrm{Co}$ and $\mathrm{Ni}$ ) (Fig. 3e, $\mathrm{f}$ and S8, Table S1). The $\mathrm{P}_{\mathrm{ga}}$ and $\mathrm{P}_{\mathrm{gd}}$ were thereby tuned by the metal centers: $\mathrm{P}_{\mathrm{ga}} / \mathrm{P}_{\mathrm{gd}}(\mathrm{Fe})>\mathrm{P}_{\mathrm{ga}} / \mathrm{P}_{\mathrm{gd}}(\mathrm{Co})>\mathrm{P}_{\mathrm{ga}} / \mathrm{P}_{\mathrm{gd}}(\mathrm{Ni})$. Since the switching pressure is exponentially correlated to the temperature, it increases substantially at elevated temperature. For example, at $298 \mathrm{~K}$, the $\mathrm{P}_{\mathrm{ga}} / \mathrm{P}_{\mathrm{gd}}$ were calculated to be $31.6 / 26.7,26.7 / 20.9$, and $18.5 / 14.6$ bar when $M=F e$, Co and $\mathrm{Ni}$, respectively, two orders of magnitude higher than at $195 \mathrm{~K}$. The magnitude of the hysteresis between $\mathrm{P}_{\mathrm{ga}}$ and $\mathrm{P}_{\mathrm{gd}}$ was also affected by temperature (Fig. S8). The hysteresis gaps were found to be $4.9(\mathrm{Fe}), 5.8(\mathrm{Co})$ and $3.9(\mathrm{Ni})$ bar at $298 \mathrm{~K}, 163,290$, and 780 times their values $(3.0,2.0$, and $0.5 \mathrm{kPa})$ at $195 \mathrm{~K}$. The hysteresis in sql-1-M-NCS suggests that $\mathrm{CO}_{2}$ can be stored at lower pressure (between $\mathrm{P}_{\mathrm{gd}}$ and $\mathrm{P}_{\mathrm{ga}}$ ) than the charging pressure ( $P_{\text {ga }}$ or above).

When compared to other switching $\mathrm{CNs}$ which exhibit wide ranges of $\mathrm{CO}_{2}$ uptakes $\left(40-590 \mathrm{~cm}^{-3} \mathrm{~g}^{-1}\right)$ and switching pressures $\left(1.3-75 \mathrm{kPa}\right.$ ) at $195 \mathrm{~K}$ (Table S2 and Fig. S9a), ${ }^{21}$ sql1-M-NCS exhibit moderate uptakes and relatively low switching pressures. At elevated temperature (e.g. 298 K), sql-1-M-NCS retained almost the same uptake, whereas some benchmark switching CNs like DUT-8(Ni) and X-pcu-n-Zn tend to exhibit lower or even negligible $\mathrm{CO}_{2}$ uptakes (Table $\mathrm{S} 2$ and Fig. S9b), ${ }^{31,36}$ due to $\mathrm{P}_{\mathrm{ga}}$ values (e.g. $>35$ bar) that are beyond the maximum testing pressures. The prototypical switching sql CN, ELM-11, was observed to exhibit 80 and $173 \mathrm{~cm}^{-3} \mathrm{~g}^{-1}$ of $\mathrm{CO}_{2}$ uptake at the first $\left(P_{\text {ga }} 1=0.65\right.$ bar $)$ and second steps $\left(P_{\text {ga }} 2=19\right.$ bar $)$ at $298 \mathrm{~K} .54$ The distinct differences between ELM-11 and sql-1-M-NCS demonstrate the feasibility of tuning the switching pressure and even the uptake in families of sql-1 CNs.

The sorption kinetics of sorbents is also relevant to their storage and separation performance, ${ }^{56-58}$ especially for FMOMs featuring structural transitions that might control the kinetics. ${ }^{51,59-61}$ We conducted dynamic $\mathrm{CO}_{2}$ sorption studies on sql-1-M-NCS gravimetrically at $288 \mathrm{~K}$ and 1-36 bar. The $\mathrm{CO}_{2}$ pressure was elevated/reduced constantly with a maximum rate of 2.5 bar $\mathrm{min}^{-1}$ for adsorption/desorption process. It was observed that sql-1-M-NCS started adsorbing/desorbing $\mathrm{CO}_{2}$ at 11.5/7.8, 10.0/9.5 and 7.5/10.8 min (equivalent to 23.9/18.0, 20.0/13.9 and 13.5/10.7 bar) for $\mathrm{M}=\mathrm{Fe}, \mathrm{Co}$ and $\mathrm{Ni}$, respectively (Fig. 4). It is consistent with the $\mathrm{P}_{\text {ga }} / \mathrm{P}_{\text {gd }}$ values $(22.2 / 18.7$, 18.5/14.5 and 12.4/9.8 bar) calculated from the ClausiusClapeyron equation at $288 \mathrm{~K}$. We determined that it took $7.5 / 5$, 6/6 and 5/7.5 min to reach full loading/unloading for sql-1-MNCS ( $\mathrm{M}=\mathrm{Fe}, \mathrm{Co}$, and $\mathrm{Ni}$, respectively), indicating $c a .12 .5 \mathrm{~min}$ for a sorption cycle and $22 \mathrm{~cm}^{-3} \mathrm{~g}^{-1} \mathrm{~min}^{-1}$ for the average sorption rate. It was reported that ELM-11 reaches full loading of $\mathrm{CH}_{4}\left(\mathrm{ca} .80 \mathrm{~cm}^{-3} \mathrm{~g}^{-1}\right)$ in $10 \mathrm{~min}$ at $303 \mathrm{~K}^{43}$ Such sorption

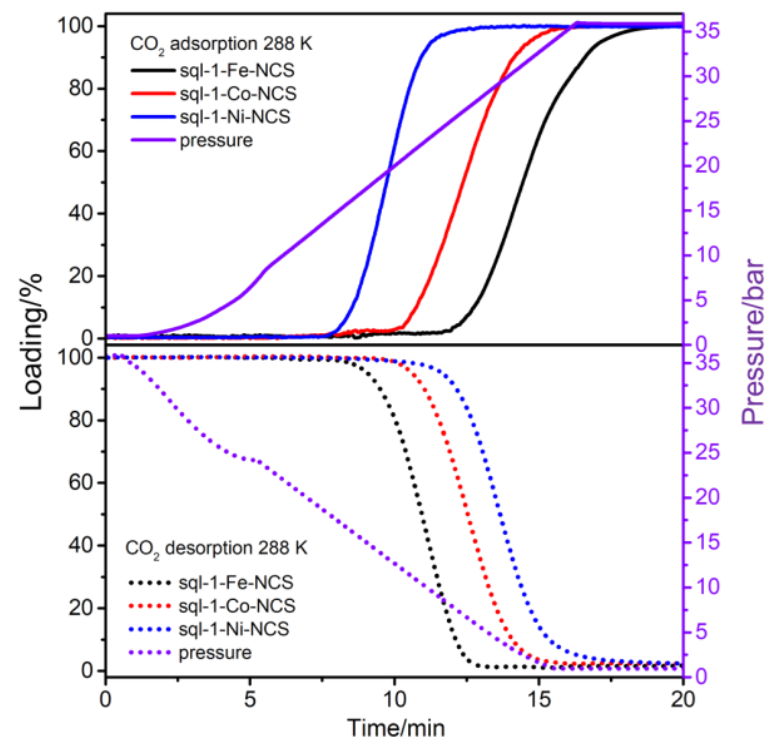

Fig. 4 Kinetics of $\mathrm{CO}_{2}$ adsorption (top) and desorption (bottom) for sql-1-M-NCS (M = Fe, Co and Ni) at $288 \mathrm{~K}$.

kinetics of sql CNs is comparable or even superior to some rigid sorbents. ${ }^{56,62}$

To better understand the switching mechanism of sql-1-MNCS, in situ $\mathrm{CO}_{2}$ loaded synchrotron PXRD experiments (Fig. S2) and molecular simulations were conducted. As revealed by Fig. 5 , the cavity size of sql-1-M-NCS $\mathbf{3} \mathbf{C O}_{2}$ remains unchanged compared to that of sql-1-M-NCS, however, the cavity geometry deforms from a rhombus in the closed phase to a square in the open phase accompanied by an interlayer distance increase from 4.5 to $5.4 \AA$. Such intra-network and internetwork deformations induced by guest molecules are quite common amongst switching $\mathrm{CNs} .^{21}$ In addition, the bpy ligand twists by $10.3^{\circ}(\mathrm{Fe}), 9.6^{\circ}(\mathrm{Co})$, and $8.9^{\circ}(\mathrm{Ni})$ to accommodate the $\mathrm{CO}_{2}$ molecules which occupy the interlayer and cavity voids as visualised by molecular simulations. It also reveals that $\left[\mathrm{CO}_{2}\right]_{3}$ cluster units are formed ( $\mathrm{C} \cdots \mathrm{O}$ distance: $2.755-3.265 \AA$ ) in the cavities of sql-1-M-NCS· $\mathbf{3} \mathbf{C O}_{2}$ and propagate along $a$ axis (Fig. S10-12). Each strand of $\left\{\left[\mathrm{CO}_{2}\right]_{3}\right\}_{n}$ is constrained in half of the cavity thanks to the ABAB stack mode of layers. Notably, the SC$\mathrm{N}-\mathrm{M}$ angles are compressed to $144.9^{\circ}$ (Fe), $156.1^{\circ}$ (Co) and $162.1^{\circ}(\mathrm{Ni})$ in the open phases, corresponding to a change of $25.5^{\circ}, 14.8^{\circ}$, and $7.4^{\circ}$ from those in the closed phases, respectively. The magnitude of deformation regarding the torsion angles of bpy and the angles of SC-N-M follows the trend of $\mathrm{Fe}>\mathrm{Co}>\mathrm{Ni}$ and is consistent with their $\mathrm{CO}_{2}$ switching pressures.

\section{Conclusions}

In conclusion, we report herein the switching behavior of three sql-1-M-NCS CNs through $\mathrm{CO}_{2}$ sorption under equilibrium and dynamic conditions. Although metal cation substitution is a simple crystal engineering strategy for modulating the properties of MOMs, to our knowledge this is the first example of switching $\mathrm{CNs}$ that retain stepped sorption isotherms across 


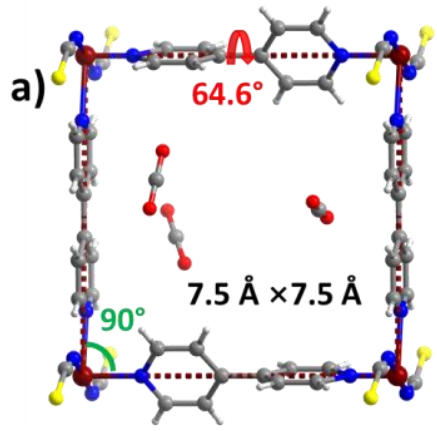

b)

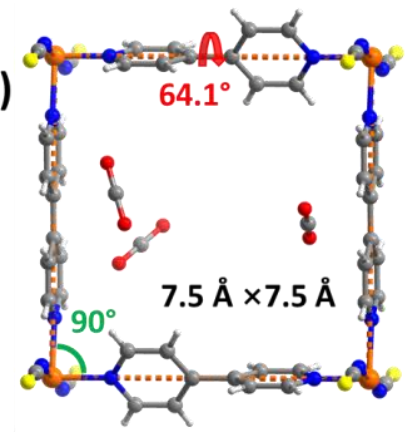

c)

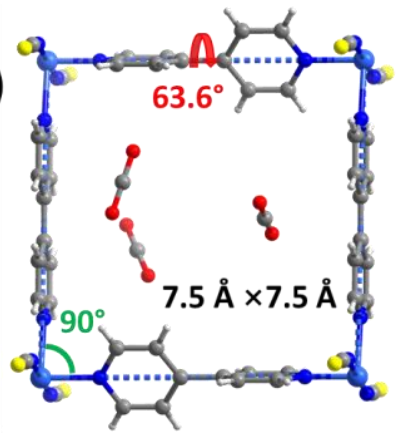

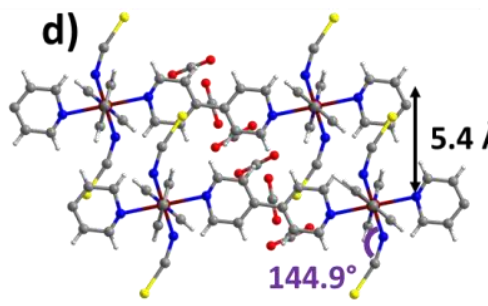
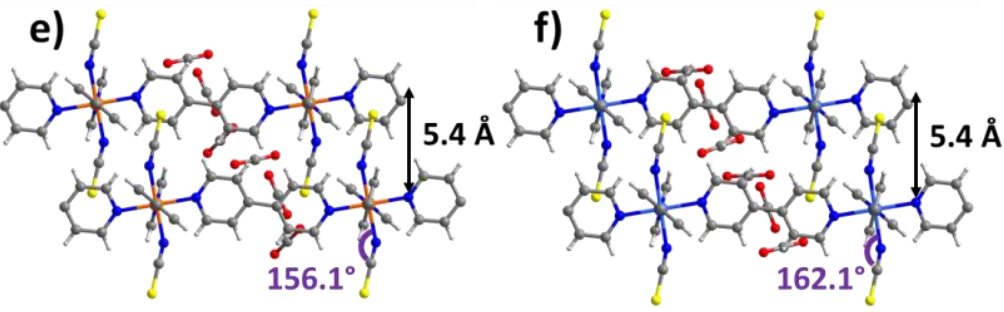

$5.4 \AA$

Fig. 5 Comparison of the crystal structures of sql-1-M-NCS.3CO . $a, d) M=F e ; b, e) ~ M=C o ; c, f) M=N i$.

three metal nodes. Crystallographic and modelling studies reveal that the metal centers affect the conformations in sql-1M-NCS $3 \mathbf{C O}_{2}$, which in turn reflect the switching pressure required for the structural transition. While several metrics such as kinetics, hydrophobicity and recyclability ${ }^{50}$, are favorable in sql-1-M-NCS, their working capacity, a key metric for gas storage, could be improved. This is particularly the case for ANG, for which the latest DOE target is $700 \mathrm{~cm}^{-3} \mathrm{~g}^{-1}$ or $263 \mathrm{~cm}^{-3}$ $\mathrm{cm}^{-3} .{ }^{63}$ Unfortunately, even the "softest" sql-1-M-NCS (i.e. sql1-Ni-NCS) exhibited negligible $\mathrm{CH}_{4}$ uptake below 60 bar at 298 $\mathrm{K}$ (Fig. S13). This is most likely because $\mathrm{CH}_{4}$ interacts weakly with host frameworks compared to $\mathrm{CO}_{2}$. In contrast, stronger binding aromatics such as xylenes adsorb ca. $87 \mathrm{wt} \%$ in sql-1-Co-NCS and we recently reported that ELM-11 (sql-1-Cu-BF 4 ) adsorbs up to $245 \mathrm{~cm}^{-3} \mathrm{~g}^{-1}$ of $\mathrm{C}_{2} \mathrm{H}_{2}$ via four sorption steps. ${ }^{47,51}$ The findings herein suggest that adsorbate-dependent uptake and switching pressure in families of sqI CNs are likely to be a common feature of such switching $\mathrm{CNs}$ and the study of other hydrocarbons will be conducted.

\section{Experimental section}

\section{Synthesis of square lattice (sql) coordination networks}

$\left[\mathrm{Fe}(\mathrm{bpy})_{2}(\mathrm{NCS})_{2}\right]_{\mathrm{n}}$ (sql-1-Fe-NCS) was prepared by water slurry method. $\mathrm{FeSO}_{4} \cdot 7 \mathrm{H}_{2} \mathrm{O}(10 \mathrm{mmol}, 2.78 \mathrm{~g}), \mathrm{NaSCN}(20 \mathrm{mmol}, 1.62$ g) and 4,4'-bipyridine (20 mmol, $3.12 \mathrm{~g})$ were added to $50 \mathrm{~mL}$ water in a $100 \mathrm{~mL}$ bottle. The slurry was stirred continuously for $3 \mathrm{~h}$ at room temperature to form the precursor $\left\{\left[\mathrm{Fe}(\mathrm{bpy})(\mathrm{NCS})_{2}\left(\mathrm{H}_{2} \mathrm{O}\right)_{2}\right] \cdot b p y\right\}_{n}$ which was then filtered, washed with water and air-dried (yield $~ 95 \%$ ). The precursor powder was activated at $50^{\circ} \mathrm{C}$ in vacuo for $5 \mathrm{~h}$ to transform to the sql coordination network: sql-1-Fe-NCS.

$\left[\mathrm{Ni}(\mathrm{bpy})_{2}(\mathrm{NCS})_{2}\right]_{\mathrm{n}}$ (sql-1-Ni-NCS) was prepared by the same method as described above except that the metal salt $\mathrm{FeSO}_{4} \cdot 7 \mathrm{H}_{2} \mathrm{O}$ was replaced by $\mathrm{NiSO}_{4} \cdot 6 \mathrm{H}_{2} \mathrm{O}(10 \mathrm{mmol}, 2.63 \mathrm{~g})$.

\section{Synchrotron Powder X-ray Diffraction}

Synchrotron PXRD data was obtained from beamline I11 at the Diamond Light Source $(\lambda=0.82455(2) \AA$ and zero point $=$ $\left.0.01826(1)^{\circ}\right)$. Powder sample sealed in a $\Phi=0.5 \mathrm{~mm}$ capillary tube was measured at $195 \mathrm{~K}$ under vacuum using positional scanning detector (PSD). After that, $\mathrm{CO}_{2}$ (195K, 1 bar) was filled into the capillary tube and powder X-ray data was collected until sample stabilized. The data was used for structure solution and refinement of sql-1-Fe-NCS and sql-1-M-NCS $\mathbf{3} \mathbf{C O}_{\mathbf{2}}(\mathrm{M}=\mathrm{Fe}$ and $\mathrm{Ni})$. Analysis of the powder data was carried out in TOPAS Academic and FullProf. The previously reported crystal structures of sql-1-Co-NCS and sql-1-Co-NCS $\mathbf{3} \mathbf{C O}_{\mathbf{2}}$ were used as starting templates. ${ }^{50}$ Lattice parameters were determined using the Pawley method. The $\mathrm{CO}_{2}$ location was not determined by synchrotron PXRD refinement while it was modelled by molecular simulation (see simulation section below). Crystallographic data (CCDC number: 2106581-2106583) is summarized in Table S3 and comparative patterns for the observed and calculated intensities including their differences are presented in Fig. S3.

\section{Density Functional Theory (DFT) Calculations}

All periodic DFT calculations were carried out using the Castep as implemented in the Materials Studio package. Vanderbilttype ultrasoft pseudopotentials and the generalized gradient approximation (GGA) with the Perdew-Burke-Ernzerhof (PBE) exchange correlation were used for all structure calculations. A semi-empirical dispersion correction was included in the calculation to take the van der Waals interactions into account. A cutoff energy of $544 \mathrm{eV}$ and a $2 \times 3 \times 2 \mathrm{k}$-point mesh (generated using the Monkhorst-Pack scheme) were found to be sufficient for total energy to converge within $0.01 \mathrm{meV}^{2}$ atom $^{-1}$. The starting structures (sql-1-M-NCS· $\mathbf{3} \mathbf{C O}_{\mathbf{2}}$ ) were obtained from the synchrotron PXRD refinement as described above. Three $\mathrm{CO}_{2}$ 
molecules per formula unit were added into each structure based on $\mathrm{CO}_{2}$ sorption studies and were set flexible to allow the optimization of their binding sites. All the simulations on the structures were conducted in $P 1$ space group.

\section{Thermogravimetric Analysis (TGA)}

TGA for all the compounds were carried out under $\mathrm{N}_{2}$ atmosphere in a TA instruments Q50 thermal analyzer between

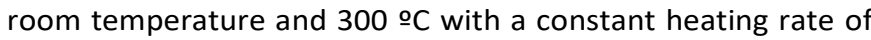
$10 \stackrel{\circ}{ } \mathrm{C} / \mathrm{min}$.

\section{Low Pressure $\mathrm{CO}_{2}$ Adsorption}

Low pressure $\mathrm{CO}_{2}$ adsorption experiments (up to 1 bar) of sql1-M-NCS ( $\mathrm{M}=\mathrm{Fe}$ and $\mathrm{Ni}$ ) were conducted on the Micromeritics TriStar II PLUS 3030 instrument at $195 \mathrm{~K}$ which was maintained by a $4 \mathrm{~L}$ Dewar flask filled with the mixture of acetone and dry ice. High-purity $\mathrm{CO}_{2}$ was used as received from BOC Gases Ireland, CP grade (99.995\%).

\section{High Pressure $\mathrm{CO}_{2}$ Adsorption}

High pressure $\mathrm{CO}_{2}$ isotherms of sql-1-M-NCS ( $\mathrm{M}=\mathrm{Fe}$ and $\mathrm{Ni}$ ) were collected on a Micromeritics HPVA II-100 instrument at different temperatures $(273-298 \mathrm{~K})$. The activated sample ( $c a$. $300 \mathrm{mg}$ ) was further degassed in situ for 1 hour before the measurements. Free spaces were determined at 0.7 bar Helium (He) and $25{ }^{\circ} \mathrm{C}$. A background correction was performed by subtracting the adsorption of the empty sample cell from the obtained isotherms.

\section{Water Vapor Sorption}

Water vapor sorption measurements were conducted using a Surface Measurement Systems DVS Vacuum at 298 K. Samples of ELM-11 (purchased from TCl) and sql-1-M-NCS (M = Fe and $\mathrm{Ni})$ were further degassed under vacuum ( $1 \times 10^{-4}$ Torr) in-situ and stepwise increase in relative pressure from 0 to $90 \%$ were controlled by equilibrated weight changes of the sample $(\mathrm{dM} / \mathrm{dT}=0.01 \% / \mathrm{min})$. Vacuum pressure transducers were used with ability to measure from $1 \times 10^{-6}$ to 760 Torr with a resolution of $0.01 \%$. Approximately $10 \mathrm{mg}$ of sample was used for each experiment. The mass of the sample was determined by comparison to an empty reference pan and recorded by a highresolution microbalance with a precision of $0.1 \mu \mathrm{g}$.

\section{Dynamic $\mathrm{CO}_{2}$ Sorption study}

Dynamic $\mathrm{CO}_{2}$ sorption experiments were carried out using a Hiden Isochema XEMIS microbalance at $288 \mathrm{~K}$. In each experiment, around $20 \mathrm{mg}$ of sample (sql-1-M-NCS) was used and further evacuated in situ at $323 \mathrm{~K}$ for $5 \mathrm{~h}$. Pressure was then maintained at 1 bar without pumping out until mass equilibrium was reached. The pressure was first elevated from 1 to 36 bar, held until mass equilibrium was reached, and then reduced from 36 to 1 bar with a maximum constant rate of $2.5 \mathrm{bar} / \mathrm{min}$. Background calibration was applied by repeating the same procedure except that the sql-1-M-NCS sample was replaced by a $20 \mathrm{mg}$ counterweight in the sample cell.

\section{Author Contributions}

Shi-Qiang Wang: conceptualization, methodology, investigation, formal analysis, writing - original draft; Shaza Darwish: investigation, writing - review \& editing; Debobroto Sensharma: investigation, writing - review \& editing; Michael J. Zaworotko: supervision, funding acquisition, writing - review \& editing.

\section{Conflicts of interest}

There are no conflicts to declare.

\section{Acknowledgements}

M. J. Z. would like to acknowledge the support of Irish Research Council (IRCLA/2019/167) and Science Foundation Ireland (13/RP/B2549 and 16/IA/4624). We thank Dr. Claire Murray and Dr. Chiu C. Tang at the Diamond Light Source, UK for the access to the synchrotron X-ray diffraction beamline i11 (EE20500). S.Q. W. would also like to thank his colleagues, Mr. Daniel O'Hearn, Dr. Andrey Bezrukov and Dr. Soumya Mukherjee, for their assistance at Diamond Light Source.

\section{Notes and references}

1 S. Kitagawa, Angew. Chem. Int. Ed. 2015, 54, 10686-10687.

2 C. M. Simon, J. Kim, D. A. Gomez-Gualdron, J. S. Camp, Y. G. Chung, R. L. Martin, R. Mercado, M. W. Deem, D. Gunter, M. Haranczyk, D. S. Sholl, R. Q. Snurr and B. Smit, Energy Environ. Sci., 2015, 8, 1190-1199.

3 M. Thommes, K. Kaneko, A. V. Neimark, J. P. Olivier, F. Rodriguez-Reinoso, J. Rouquerol and K. S. Sing, Pure Appl. Chem., 2015, 87, 1051-1069.

4 J. A. Mason, J. Oktawiec, M. K. Taylor, M. R. Hudson, J. Rodriguez, J. E. Bachman, M. I. Gonzalez, A. Cervellino, A. Guagliardi, C. M. Brown, P. L. Llewellyn, N. Masciocchi and J. R. Long, Nature, 2015, 527, 357-361.

5 J. J. Perry IV, J. A. Perman and M. J. Zaworotko, Chem. Soc. Rev., 2009, 38, 1400-1417.

6 T. R. Cook, Y.-R. Zheng and P. J. Stang, Chem. Rev., 2012, 113, 734-777.

7 L. R. MacGillivray, Metal-organic frameworks: design and application, John Wiley \& Sons, 2010.

8 D. Farrusseng, Metal-organic frameworks: applications from catalysis to gas storage, John Wiley \& Sons, 2011.

9 S. Kitagawa, R. Kitaura and S. i. Noro, Angew. Chem. Int. Ed., 2004, 43, 2334-2375.

10 S. R. Batten, S. M. Neville and D. R. Turner, Coordination polymers: design, analysis and application, Royal Society of Chemistry, 2009.

11 C. Janiak and J. K. Vieth, New J. Chem., 2010, 34, 2366-2388.

12 D. J. O'Hearn, A. Bajpai and M. J. Zaworotko, Small, 2021 2006351.

13 J.-R. Li, R. J. Kuppler and H.-C. Zhou, Chem. Soc. Rev., 2009, 38, 1477-1504.

14 B. Li, H.-M. Wen, Y. Cui, W. Zhou, G. Qian and B. Chen, Adv. Mater., 2016, 28, 8819-8860.

15 B. Moulton and M. J. Zaworotko, Chem. Rev., 2001, 101, 16291658.

16 N. W. Ockwig, O. Delgado-Friedrichs, M. O'Keeffe and O. M. Yaghi, Acc. Chem. Res., 2005, 38, 176-182. 
17 P. Z. Moghadam, A. Li, X.-W. Liu, R. Bueno-Perez, S.-D. Wang S. B. Wiggin, P. A. Wood and D. Fairen-Jimenez, Chem. Sci., 2020, 11, 8373-8387.

18 A. Schneemann, V. Bon, I. Schwedler, I. Senkovska, S. Kaskel and R. A. Fischer, Chem. Soc. Rev., 2014, 43, 6062-6096.

19 S. Horike, S. Shimomura and S. Kitagawa, Nat. Chem., 2009, 1, 695-704.

20 Q.-Y. Yang, P. Lama, S. Sen, M. Lusi, K. J. Chen, W. Y. Gao, M. Shivanna, T. Pham, N. Hosono, S. Kusaka, J. J. IV. Perry, S. Ma, B. Space, L. J. Barbour, S. Kitagawa and M. J. Zaworotko, Angew. Chem. Int. Ed., 2018, 57, 5684-5689.

21 S.-Q. Wang, S. Mukherjee and M. J. Zaworotko, Faraday Discuss., 2021, 231, 9-50.

22 S. Mukherjee and M. J. Zaworotko, Trends Chem., 2020, 2, 506-518.

23 J.-P. Zhang, H.-L. Zhou, D.-D. Zhou, P.-Q. Liao and X.-M. Chen, Natl. Sci. Rev., 2018, 5, 907-919.

24 S. K. Elsaidi, M. H. Mohamed, D. Banerjee and P. K. Thallapally, Coord. Chem. Rev., 2018, 358, 125-152.

25 S. Henke, A. Schneemann, A. Wuetscher and R. A. Fischer, J. Am. Chem. Soc., 2012, 134, 9464-9474.

26 A. Schneemann, P. Vervoorts, I. Hante, M. Tu, S. Wannapaiboon, C. Sternemann, M. Paulus, D. C. F. Wieland, S. Henke and R. A. Fischer, Chem. Mater., 2018, 30, 16671676.

27 N. A. Ramsahye, T.-K. Trung, S. Bourrelly, Q.-Y. Yang, T. Devic, G. Maurin, P. Horcajada, P. L. Llewellyn, P. Yot, C. Serre, Y. Filinchuk, F. Fajula, G. Ferey and P. Trens, J. Phys. Chem. C, 2011, 115, 18683-18695.

28 T. Devic, F. Salles, S. Bourrelly, B. Moulin, G. Maurin, P. Horcajada, C. Serre, A. Vimont, J.-C. Lavalley, H. Leclerc, G. Clet, M. Daturi, P. L. Llewellyn, Y. Filinchuk and G. Ferey, J. Mater. Chem., 2012, 22, 10266-10273.

29 M. K. Taylor, T. Runčevski, J. Oktawiec, M. I. Gonzalez, R. L. Siegelman, J. A. Mason, J. Ye, C. M. Brown and J. R. Long, J. Am. Chem. Soc., 2016, 138, 15019-15026.

30 A.-X. Zhu, Q.-Y. Yang, A. Kumar, C. Crowley, S. Mukherjee, K.J. Chen, S.-Q. Wang, D. O' Nolan, M. Shivanna and M. J. Zaworotko, J. Am. Chem. Soc., 2018, 140, 15572-15576.

31 A.-X. Zhu, Q.-Y. Yang, S. Mukherjee, A. Kumar, C.-H. Deng, A. A. Bezrukov, M. Shivanna and M. J. Zaworotko, Angew. Chem. Int. Ed., 2019, 58, 18212-18217.

32 S. Bourrelly, P. L. Llewellyn, C. Serre, F. Millange, T. Loiseau and G. Férey, J. Am. Chem. Soc., 2005, 127, 13519-13521.

33 P. L. Llewellyn, P. Horcajada, G. Maurin, T. Devic, N. Rosenbach, S. Bourrelly, C. Serre, D. Vincent, S. Loera-Serna, Y. Filinchuk and G. Ferey, J. Am. Chem. Soc., 2009, 131, 1300213008.

34 J. P. Mowat, V. R. Seymour, J. M. Griffin, S. P. Thompson, A. M. Slawin, D. Fairen-Jimenez, T. Düren, S. E. Ashbrook and P. A. Wright, Dalton Trans., 2012, 41, 3937-3941.

35 S. Galli, N. Masciocchi, V. Colombo, A. Maspero, G. Palmisano, F. J. López-Garzón, M. Domingo-García, I. Fernández-Morales, E. Barea and J. A. R. Navarro, Chem. Mater., 2010, 22, 16641672.

36 N. Klein, H. C. Hoffmann, A. Cadiau, J. Getzschmann, M. R. Lohe, S. Paasch, T. Heydenreich, K. Adil, I. Senkovska, E. Brunner and K, Stefan, J. Mater. Chem., 2012, 22, 1030310312.

37 C. M. McGuirk, T. Runčevski, J. Oktawiec, A. Turkiewicz, M. K. Taylor and J. R. Long, J. Am. Chem. Soc, 2018, 140, 1592415933.

38 T. G. Mitina and V. A. Blatov, Cryst. Growth Des., 2013, 13, 1655-1664.

39 M. J. Zaworotko, Chem. Commun. 2001, 1-9.

40 M. Fujita, Y. J. Kwon, S. Washizu and K. Ogura, J. Am. Chem. Soc., 1994, 116, 1151-1152.

41 D. Li and K. Kaneko, Chem. Phys. Lett., 2001, 335, 50-56.
42 A. Kondo, H. Noguchi, S. Ohnishi, H. Kajiro, A. Tohdoh, Y. Hattori, W.-C. Xu, H. Tanaka, H. Kanoh and K. Kaneko, Nano Lett., 2006, 6, 2581-2584

$43 \mathrm{H}$. Kanoh, A. Kondo, H. Noguchi, H. Kajiro, A. Tohdoh, Y. Hattori, W.-C. Xu, M. Inoue, T. Sugiura, K. Morita, H. Tanaka, T. Ohba and K. Kaneko, J. Colloid Interface Sci., 2009, 334, 1-7.

$44 \mathrm{H}$. Kajiro, A. Kondo, K. Kaneko and H. Kanoh, Int. J. Mol. Sci., 2010, 11, 3803-3845.

45 V. Bon, I. Senkovska, D. Wallacher, A. Heerwig, N. Klein, I. Zizak, R. Feyerherm, E. Dudzik and S. Kaskel, Microporous Mesoporous Mater., 2014, 188, 190-195.

46 L. Li, R. Krishna, Y. Wang, X. Wang, J. Yang and J. Li, Eur. J. Inorg. Chem., 2016, 2016, 4457-4462.

47 S.-Q. Wang, X.-Q. Meng, M. Vandichel, S. Darwish, Z. Chang, X.-H. Bu and M. J. Zaworotko, ACS Appl. Mater. Interfaces, 2021, 13, 23877-23883.

48 A. Kondo, A. Chinen, H. Kajiro, T. Nakagawa, K. Kato, M Takata, Y. Hattori, F. Okino, T. Ohba, K. Kaneko and H. Kanoh, Chem. - Eur. J., 2009, 15, 7549-7553.

49 J. Lu, T. Paliwala, S. C. Lim, C. Yu, T. Y. Niu and A. J. Jacobson, Inorg. Chem., 1997, 36, 923-929.

50 S.-Q. Wang, Q.-Y. Yang, S. Mukherjee, D. O'Nolan, E. PatykKaźmierczak, K.-J. Chen, M. Shivanna, C. Murray, C. C. Tang and M. J. Zaworotko, Chem. Commun., 2018, 54, 7042-7045.

51 S.-Q. Wang, S. Mukherjee, E. Patyk-Kaźmierczak, S. Darwish, A. Bajpai, Q.-Y. Yang and M. Zaworotko, Angew. Chem. Int. Ed., 2019, 58, 6630-6634.

52 Z. Yugen, J. Li, W. Deng, N. Masayoshi and I. Tsuneo, Chem Lett., 1999, 28, 195-196.

53 H. Irving and R. J. P. Williams, J. Chem. Soc. 1953, 3192-3210.

54 M. Ichikawa, A. Kondo, H. Noguchi, N. Kojima, T. Ohba, H. Kajiro, Y. Hattori and H. Kanoh, Langmuir, 2016, 32, 97229726.

55 S. Hiraide, H. Tanaka, N. Ishikawa and M. T. Miyahara, ACS Appl. Mater. Interfaces, 2017, 9, 41066-41077.

56 Y. Wang and D. Zhao, Cryst. Growth Des., 2017, 17, 2291 2308.

57 P. Nugent, Y. Belmabkhout, S. D. Burd, A. J. Cairns, R. Luebke, K. Forrest, T. Pham, S. Q. Ma, B. Space, L. Wojtas, M. Eddaoudi and M. J. Zaworotko, Nature, 2013, 495, 80-84.

58 K. Li, D. H. Olson, J. Seidel, T. J. Emge, H. Gong, H. Zeng and J. Li, J. Am. Chem. Soc., 2009, 131, 10368-10369.

59 D. Tanaka, K. Nakagawa, M. Higuchi, S. Horike, Y. Kubota, T. C. Kobayashi, M. Takata and S. Kitagawa, Angew. Chem. Int. Ed., 2008, 47, 3914-3918.

60 A. M. Kałuża, S. Mukherjee, S.-Q. Wang, D. J. O'Hearn and M. J. Zaworotko, Chem. Commun., 2020, 56, 1940-1943.

61 F. Millange, C. Serre, N. Guillou, G. Ferey and R. I. Walton, Angew. Chem., Int. Ed., 2008, 47, 4100-4105.

62 S. Choi, J. H. Drese and C. W. Jones, ChemSusChem, 2009, 2 796-854.

63 Y. He, W. Zhou and B. Chen. Current Status of Porous MetalOrganic Frameworks for Methane Storage, Metal-Organic Frameworks: Applications in Separations and Catalysis WileyVCH, 2018; pp. 163-198. 


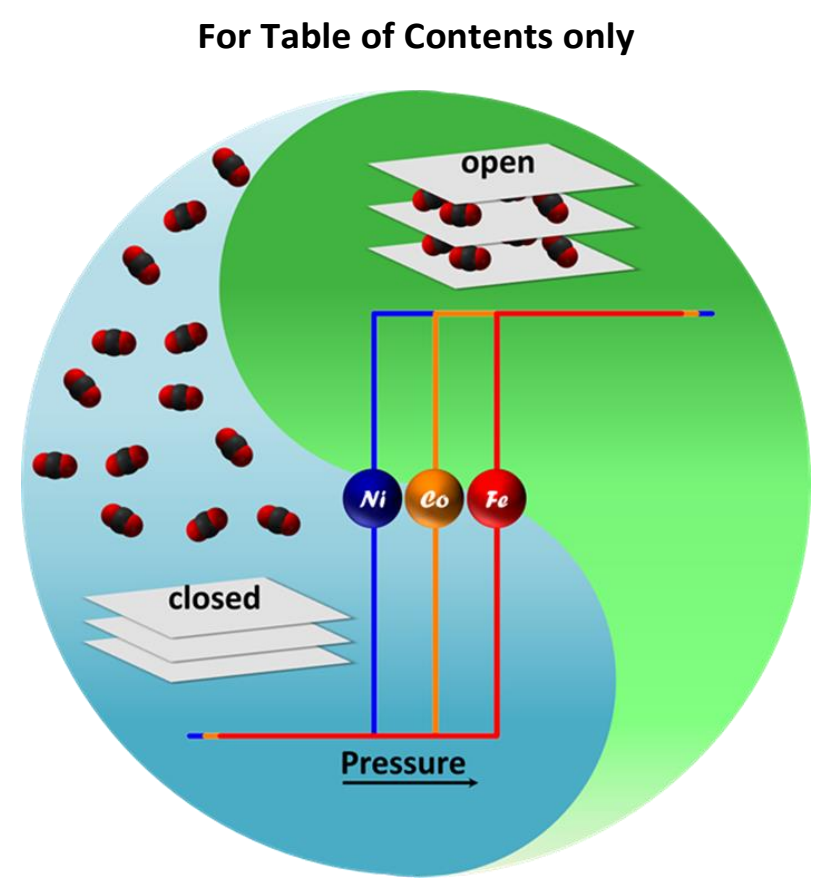

8 | J. Name., 2012, 00, 1-3 